\title{
A Study to Assess the Effectiveness of Structured Teaching Programme Regarding Knowledge on Prevention of Upper Respiratory Tract Infection Among Mothers of Toddler in Selected Hospital, Bangalore.
}

\author{
Jophin Joseph ${ }^{1}$, Jyothy George ${ }^{2}$ \\ ${ }^{1}$ Department of Nursing and Midwifery, College of Public Health and Medical Sciences, Jimma University, PO.Box:1104, Jimma, \\ ${ }^{2}$ Department of Pediatric, Narayana Hrudayalaya, Bommasandra Industrial Area, Bengaluru, Karnataka 560099, India
}

\begin{abstract}
Background: upper respiratory tract infections are the major causes for mortality and morbidity under 3 years of children. in worldwide statistics when we take every year 3.9 million deaths of toddler due to upper respiratory tract infections where as in India $15-20 \%$ of toddler admission to the hospital is due to upper respiratory tract infection the aim of the present study is to assess the effectiveness of structured teaching programme for mothers of toddler on prevention of upper respiratory tract infection. Objectives of the study is to assess the knowledge of the mothers in prevention of upper respiratory tract infection, to determine the effectiveness of structured teaching program regarding upper respiratory tract infection and to find out the association between selected demographic variable with knowledge regarding prevention of upper respiratory tract infection. Method: one group pretest posttest quasi experimental design was selected for the study. The participants were 60 mothers of toddler were included using simple random sampling from a selected hospital at Bangalore. Questionnaire is used to collect data from the subjects and the obtained data was analyzed using descriptive, inferential statistics and interpreted in terms of objectives of the study. The level of significance was set at 0.05 levels. Results: In the pre-test the subjects had inadequate knowledge with a mean of $29.25 \%$ and standard deviation of 2.26 where as in posttest there was a significant mean knowledge gain of $77.77 \%$ and standard deviation of 1.68 . The chi-square test revealed that there was a significant association of knowledge with selected demographic variables such as occupation, family income and any previous exposure to the knowledge on URT infection. Conclusion: The present study proved that the structured teaching program was significantly effective in improving the knowledge of mothers of toddler on prevention of upper respiratory tract infection. Hence the study concluded that improve the knowledge on management of upper respiratory tract infection helps to provide care, to safeguard the children and to prevent further complication.
\end{abstract}

Keywords: prevention, structured teaching programme, upper respiratory tract infection, mothers of toddler

\section{Introduction}

\section{"The future depends on what we do in the present" --Mahatma Gandhi}

Children, the hope of tomorrow, the reason to smile and the dreams of future, who has to be protected. Their tears and grief cannot be admitted and the responsibility of protecting them fall on our shoulders, we the grown-ups....Childhood is the period of disabilities and ailments as well as the period of their mental and social development. Disturbance in the childhood can bring about various consequences with regard to the growth and the development, both physically and mentally. Diseases play the most terrific role in taking away the innocent smile from their faces. Among the disease the acute respiratory tract infection contributes the major part.

Toddler period begins from one year of life and ends at third year. During their life, physical growth, maturation, acquisition of competence and psychological recognition occurs in discontinues burst. The parents feel more comfortable when the child reaches its toddler period [1]. Upper respiratory tract infections are the common problem in toddler as well as children and it is the major cause of lower respiratory tract infections, many acute respiratory infections are mild and cause few symptoms. Interventions delivered at home are usually sufficient to relieve minor discomfort and eases respiratory efforts. Warm or cool moist is a common therapeutic measure for symptomatic relief of respiratory discomfort and also management of respiratory secretions in toddler [2]. Prevention of spread of infection is very important in toddler; careful hand washing is carried out when caring for children with respiratory infections. Toddler with respiratory infection is irritable and difficult to comfort therefore, the family needs support, encouragement and practical suggestions concerning comfort measures and administration of medication [3]

In worldwide statistics when we take every year 3.9 million deaths of young children due to acute respiratory tract infections. It is estimated that Bangladesh, India, Indonesia and Nepal together account for $40 \%$ of the global acute respiratory tract infection mortality. An average child below 5 year of age suffers about 5 episodes of acute upper respiratory tract infections per year, thus accounting for about 138 million attacks. It causes about $20-40 \%$ of admission to hospitals [4]. Every year 12 million children are dying in developing countries since the first year of life.

\section{Volume 4 Issue 12, December 2015}




\section{International Journal of Science and Research (IJSR) \\ ISSN (Online): 2319-7064}

Index Copernicus Value (2013): 6.14 | Impact Factor (2014): 5.611

Some viral and bacterial diseases also cause upper respiratory tract infections in toddler. Measles killed between 7-8 million children in a year. Diphtheria and whooping cough are the other disease causes upper respiratory tract infections in children. A study conducted to determine epidemiological characteristics that are occurrence of Respiratory Syncytial Virus (RSV) infection in Croatian children with acute respiratory tract infection shows the incidence of respiratory syncytial virus $(48 \%)$ is more common among toddler [5]. Another study on childhood upper respiratory tract infection: to what degree is incidence affected by day care attendance reveals that for the children less than three years reported the incidents of $24 \%$. Upper respiratory tract infection increased risk was present for all children attending day care centers [6].

In India Acute respiratory tract infections are the leading causes of the death, about 7, 80,000 deaths among under five children annually are due to acute respiratory tract infection in addition to that it is one of the major reasons for which young children are brought to the hospital. Hospital records show that up to $13 \%$ of young child mortality in pediatric ward due to upper respiratory tract infection. The burden of the disease in terms of disability adjusted life year (DALYs) lost was 25.5 million of these 2.74 lakh due to acute respiratory tract infection [7]. Incidents in India show most of the upper respiratory tract infection in toddler, like the common cold is caused by virus [8].

Acute respiratory tract infections are usually mild, viral, and self-limiting; however, the symptoms can cause fever and make children irritable, lethargic, and uncomfortable. The treatment strategy is to minimize symptoms and discomfort. a study conducted to assess the risk and benefits of anti-biotic treatment in children with symptoms of upper respiratory infection reveals that clinical outcome was improved by the anti-biotic treatment was not associated with an increasing side effects compared with placebo.[9]. In addition to that another retrospective observational study on drugs in upper respiratory tract infection in pediatric patients in north Trinidad exhibits large proportions of young pediatric patients diagnosed with upper respiratory tract infection in north Trinidad was prescribed anti-biotic, although the inappropriate use of anti-biotic can potentiate the worldwide trend on anti-microbial resistance.[10]

Many mothers of toddler having anxiety and less awareness hence they require educational programs. A study conducted with the aim of effect of mother's education on the prevalence of severe upper respiratory tract infection among toddlers in Bangladesh suggests that the house hold poverty, children lower age, sex of the child, malnutrition, mother's lower age at child birth are risk factors of severe upper respiratory tract infection among toddler. There for improving mother's education could have significant effect on preventing upper respiratory tract infection among toddler [11]. Another randomized field trial was conducted in 52 day care centers in Canada, this study result indicate that training program for the mothers of toddler play an important role in reducing infection in children attending day care center [12].
Objectives of the study:

a) To assess the knowledge of the mothers in prevention of upper respiratory tract infection.

b) To determine the effectiveness of structured teaching program regarding upper respiratory tract infection.

c) To find out the association between selected demographic variable with knowledge regarding prevention of upper respiratory tract infection.

\section{Materials and Method}

The research design selected for this study was Quasiexperimental research design, one group pretest and posttest without control group. The study was conducted in the pediatric ward at selected hospital in Bangalore. The population consists of all the mothers of toddler admitted in pediatric ward at selected hospital in Bangalore. The sample size was 60 mother of toddler which is selected by Probability simple random sampling technique. An inclusion criterion for sampling was:

1) Mothers who are willing to participate in the study.

2)Mothers of toddler admitted and available during data collection in pediatrics ward at selected Hospital in Bangalore.

3)Mothers of toddler who are able to read and understand Kannada OR English.

\section{Description of the Tool}

Structured interview schedule was used as the research tool. The tool consists of three sections:

\section{Part I:}

It deals with demographic variable, which include age, religion, education, occupation, family income, type of family, number of children in the family, any previous exposure to knowledge and access of health information.

\section{Part II:}

This part consists of 39 questions regarding prevention of upper respiratory tract infection. The questions were phrased in a multiple choice form with 4 options as distracters and 1 correct response. The correct response is given a score of one mark and the wrong response is given a score of zero.

Section -A: It consists of 5 questions regarding General information about upper respiratory tract infection.

Section-B: It comprise of 5 questions regarding Definition and incidence of upper respiratory tract infection.

Section-C: It comprise of 4 questions regarding Etiology and Risk factors of upper respiratory tract infection.

Section-D: It comprise of 9 questions regarding Clinical manifestations of upper respiratory tract infection.

Section-E: It comprises of 16 questions regarding management, prevention and home care of upper respiratory tract infection.

\section{Part III:}

A structured teaching Programme was also prepared by the investigator which covered major areas such as meaning, definition, risk factors, types, signs and symptoms, treatment, prevention and home care of upper respiratory tract infection. 


\section{International Journal of Science and Research (IJSR) \\ ISSN (Online): 2319-7064 \\ Index Copernicus Value (2013): 6.14 | Impact Factor (2014): 5.611}

The investigator first introduced her to the participants and obtained their verbal consent. Participants were given pretest using structured interview schedule. After the pretest the investigator administered structured teaching programme regarding prevention of upper respiratory tract infection among toddlers for 20 minutes using AV aids. At the end of structured teaching programme 10 minutes was allotted for discussion. The post test was conducted after 1 day using same structured interview schedule. The same procedure was followed for all the mothers. Five mothers of toddler were assessed from 10 to 12 noon each day. The resulting knowledge score ranged as,

- Adequate knowledge 30-39 (76-100\%)

- Moderate knowledge 20-29 (51-75\%)

- In adequate knowledge $\leq 20$ (less than 50\%)

\section{Data Analysis}

1)The frequencies and percentages for the analysis of demographic variables.

2)Mean and standard deviation to assess the pre-test and post-test knowledge of mothers of toddler regarding Prevention of upper respiratory tract infection.

3)Paired, $t^{\text {ee }}$ test is used to compare the pre-test and posttest knowledge of mothers of toddler regarding Prevention of upper respiratory tract infection.

4)Chi-square test is used to associate the pretest knowledge of mothers of toddler regarding Prevention of upper respiratory tract infection with selected demographic variables.

\section{Result}

\section{a) Demographic Data}

- Majority of 28 mothers of toddlers (46.67\%) belongs to $19-25 \& 26-30$ age group and $4(6.67 \%)$ belongs to above 30 years.

- Majority of mothers of toddler 29 (48.33\%) belong Hindu religion, 26 (43.33\%) belongs to Muslims and $5(8.33 \%)$ were Christian.

- Majority of 49 mothers of toddler $(80 \%)$ were house wife, $9(15 \%)$ were daily wages and $3(5 \%)$ were monthly salaried.

- About 32 mothers of toddler (53.33\%) have previous information of upper respiratory tract infection and $28(46.67 \%)$ does not have previous information..

- About 29 mothers of toddler (48.33\%) having middle school education, 28(46.67\%) mothers are having SSLC education and $3(5 \%)$ are graduates.

- About 38 (63.33\%) mothers of toddler belongs to nuclear family and $22(36.67 \%)$ are belong to joint family

- About 32 mothers of toddler (53.33\%) are having two children in the family , $18(30 \%)$ are having one child and $10(16.67 \%)$ are having more than three children in the family

- About 22 mothers of toddler (36.67\%) have family income of Rs 1,000-2000 and 25 (41.67\%) have family income of 2001-3000, 7 (11.67) are in below 1000 and remaining 6 $(10 \%)$ have family income more than Rs 3000 .
- Majority of 29 mothers of toddler (48.33\%) access health information through TV, $16(26.68 \%)$ through newspapers, 13 (21.67) through health person and remaining $2(3.33 \%)$ through radio.

\section{b) Pretest knowledge}

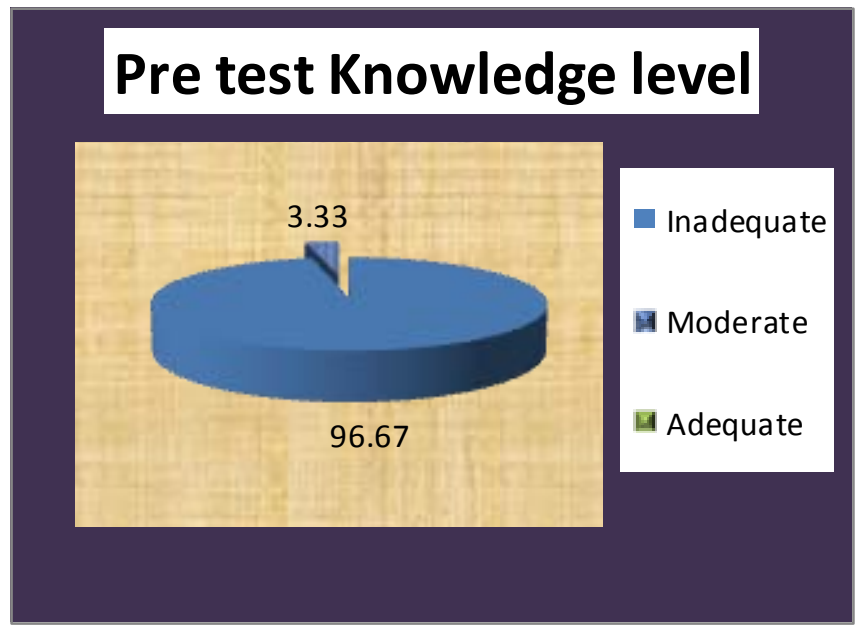

Figure 1: Pretest knowledge level on prevention of upper respiratory tract infection

Figure1 states that, About 58 mothers (96.67\%) have inadequate knowledge level on prevention of upper respiratory tract infection and about 2 mothers $(3.33 \%)$ have moderate knowledge level. It is interesting to note that none of the mothers had adequate knowledge on prevention of upper respiratory tract infection

\section{c) Posttest knowledge:}

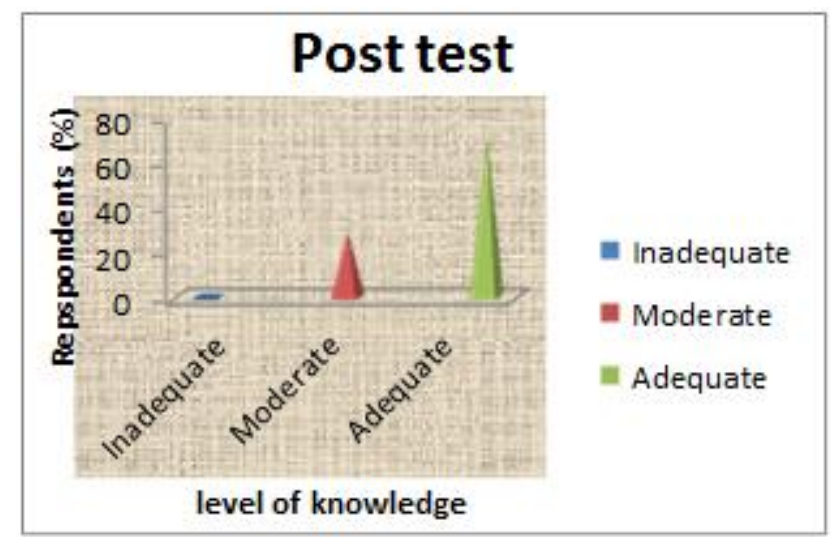

Figure 2: Posttest Knowledge level on Prevention of upper respiratory tract infection

The above figure 2 shows that 17 Mothers (22.33\%) have moderate knowledge level and 43 (71.67\%) mothers have adequate knowledge level regarding prevention of upper respiratory tract infection. 


\section{International Journal of Science and Research (IJSR) \\ ISSN (Online): 2319-7064}

Index Copernicus Value (2013): 6.14 | Impact Factor (2014): 5.611

d) Effectiveness of structured teaching program:

Table: 1: over all Pretest and Posttest Mean Knowledge score on Prevention of upper respiratory tract infection.

\begin{tabular}{|c|c|c|c|c|c|}
\hline \multirow[t]{2}{*}{ Domain } & \multirow{2}{*}{$\begin{array}{l}\text { Max. } \\
\text { Score }\end{array}$} & \multicolumn{3}{|c|}{ Respondents Knowledge } & \multirow{2}{*}{$\begin{array}{c}\text { Paired „t" } \\
\text { Test }\end{array}$} \\
\hline & & Mean & SD (\%) & Mean $(\%)$ & \\
\hline Pre test & 39 & 11.41 & 2.26 & 29.3 & \multirow{3}{*}{$56.23 * * *$} \\
\hline Post test & 39 & 30.33 & 1.68 & 77.77 & \\
\hline Enhancement & 39 & 18.92 & 2.61 & 48.51 & \\
\hline \multicolumn{6}{|c|}{ * Significant at $1 \%$ level, $t(0.01,59 \mathrm{df})=2.39$} \\
\hline
\end{tabular}

Table 1 shows that overall enhancement mean score is 18.92 , SD 2.61, and mean percentage 48.5.Paired test value is 56.23 significant at 0.01 levels hence, the structured teaching programme was effective.

Table 2: Aspects wise effectiveness of Pretest and Posttest Mean Knowledge score on Prevention of upper respiratory tract infection.

\begin{tabular}{|c|c|c|c|c|}
\hline \multirow{2}{*}{ Knowledge Aspects } & \multicolumn{3}{|c|}{ Enhancement } & Paired \\
\cline { 2 - 4 } & Mean & SD & Mean (\%) & 't' test \\
\hline General information & 2.18 & 1.11 & 43.6 & $15.2^{* *}$ \\
\hline Definition and incidence & 2 & 0.9 & 40 & $17.2^{* *}$ \\
\hline Etiology and risk factors & 2.42 & 0.83 & 60.5 & $22.6^{* *}$ \\
\hline Clinical manifestations & 4.48 & 0.92 & 49.78 & $36^{* *}$ \\
\hline $\begin{array}{c}\text { Prevention management and } \\
\text { homecare }\end{array}$ & 7.93 & 1.6 & 49.56 & $38^{* *}$ \\
\hline Combined & $\mathbf{1 8 . 9 2}$ & $\mathbf{2 . 6 1}$ & $\mathbf{4 8 . 5 1}$ & $\mathbf{5 6 . 2 3 * *}$ \\
\hline **Significant at 1\% level, t $(0.01,59 \mathrm{df})=2.39$ \\
\hline
\end{tabular}

e) Association between selected demographic variable with Posttest knowledge regarding prevention of upper respiratory tract infection.

Table 3: Association between selected demographic variable with Posttest knowledge regarding prevention of upper respiratory tract infection

\begin{tabular}{|c|c|c|c|c|}
\hline Sl. No & Area & $d f$ & $\begin{array}{c}\text { Chi square } \\
\text { value }\end{array}$ & $\begin{array}{c}\text { Level of } \\
\text { significance }\end{array}$ \\
\hline 1 & Occupation & 2 & 7.87 & $\begin{array}{c}\text { Highly } \\
\text { Significance }\end{array}$ \\
\hline 2 & Family income & 3 & 13.1 & $\begin{array}{c}\text { Highly } \\
\text { Significance }\end{array}$ \\
\hline 3 & $\begin{array}{c}\text { Any previous exposure } \\
\text { to the knowledge on } \\
\text { URT infection }\end{array}$ & 1 & 16.46 & $\begin{array}{c}\text { Highly } \\
\text { Significance }\end{array}$ \\
\hline
\end{tabular}

Significant at 5\% level (i.e., 0.05 levels)

The analysis of association of selected demographic variables with posttest level of knowledge using chi-square test revealed that there was association between posttest level of knowledge and selected demographic variables in occupation, family income and exposure to previous knowledge are found to be significant at 0.05 level where as type of family, age group, religion, education, number of children, and access for health information are found to be non-significant at 0.05 .

\section{Discussion}

The present study depicts Pretest score was 29.25\%, revealing poor knowledge whereas posttest knowledge score was $77.77 \%$ revealing good knowledge. The mean difference was $48.51 \%$ shows the effectiveness of structured teaching program.

\section{Implication}

- Nursing practice: Nurses should be involved in planning prevention of upper respiratory tract infection for Mothers of toddler. Nurses should incorporate the concept of different levels of prevention in their practice.

- Nursing education: Nurse Educator can teach the mothers of toddler to acquire adequate knowledge in preventions of upper respiratory tract infection.

- Nursing administration: Nurse Administrators can plan and conduct a short term educational program for mothers of toddler to improve their knowledge on prevention of upper respiratory tract infection. Nurse administrator should plan in-service education program for nurses to enhance their knowledge.

- Nursing research: Based on this finding the researchers can conduct further studies on awareness and improvement of knowledge of mothers of toddler regarding prevention of upper respiratory tract infection on large samples. The study will motivate the beginning researcher and to conduct studies with different variables on large scale.

\section{Limitation}

The present study has following limitations:

- Only 60 mothers of toddler were selected as sample.

- Study was conducted only in K C General Hospital, Bangalore; hence generalization is possible only to the selected settings.

\section{Recommendations}

- Similar study can be undertaken with a larger number of samples to generalize the findings.

- A similar study can be undertaken with control group design.

- A comparative study can be done in all the hospitals at Bangalore.

\section{Ethical Clearance}

The proposed study was conducted after the approval of dissertation committee of The Karnataka College of Nursing. Permission was obtained from the Medical superidentent, $\mathrm{K}$ C General Hospital Bangalore. Consent of each subject was obtained before starting the data collection. Assurance was given to them that the anonymity of each individual would be maintained. 


\section{Acknowledgement}

"God is great "My sincere special gratitude to Mrs. Jyothy George for helping me to prepare this article, I owe my sincere thanks and gratitude to all those who have contributed towards the successful completion of this endeavor.

\section{References}

[1] Marilyn j.hockenberry, Wonges essential of pediatric nursing, seventh edition, Elsevier publications, New Delhi, 2003, page no; 237-240.

[2] Paulette d.rollant and Joyce Hamlin, Pediatric nursing, Mosby publishing excellence, St. Louis, mo., 1996, page no: $153-160$.

[3] Dorothy Marlow and Barbara a.redding, text book of pediatric nursing, $\mathrm{I}^{\mathrm{ST}}$ edition, Elsevier publications, New Delhi, 2006, page no:721-735.

[4] I clement, Pediatric nursing, $\mathrm{I}^{\mathrm{ST}}$ edition, a.p Jain and co publishers, New Delhi, 2006, page no: 97-107.

[5] Shon beck "effectiveness of educational intervention in modifying parental attitude the use of antibiotics". www.pediatrics.org/111/548, 2005.

[6] Carrabin. H, "child hood URTI: to what degree is incidence affected by day care center attendance". http/www.pediatrics.aappulications.org/103/3/556, 2008.

[7] Jessie m.chellappa, Pediatric nursing, $\mathrm{I}^{\mathrm{ST}}$ edition, Gajanana book publishers and distributers, Bangalore, 2002, page no: 139-148.

[8] Fred .m.heureting and Christopher king, text book of pediatric emergency procedures, Williams and Wilkins company publishers, Maryland, 1997, page no: 621-650

[9] Stephan louche, "the risk and benefits of antibiotic treatment in treating URTI",http/www.mediscape/707522, 2007.

[10] Wald er.guerra, "how safe and effective is Echinacea purpura at reducing the duration and severity of URTI in children", www.medscape.com/5213183, 2008.

[11] Kazi md. Abdul kalam, "effect of mothers education on prevalence of severe URTI among toddler in Bangladesh", akazad71@gmail.com, 2004.

[12] Taylor J A, "effectiveness of training program for reduce URTI among toddler in day care center at Canada" www.pediatric.org/111/5/54, 2005.

\section{Author Profile}

Mr. Jophin Joseph received M.Sc. in pediatric nursing from The Karnataka College of nursing, Bangalore. Currently he is working as a lecturer in department of nursing, Jimma University, Ethiopia.

Mrs. Jyothy George received M.Sc. in pediatric nursing from Rajarajeswari College of nursing Bangalore, there after she was working as a staff nurse in Narayana hrudayalaya, Bangalore. 